Hope College

Hope College Digital Commons

Faculty Publications

3-2014

\title{
Do Religious Affirmations, Religious Commitments, or General Commitments Mitigate the Negative Effects of Exposure to Thin Ideals?
}

\author{
Mary Inman \\ Hope College, inman@hope.edu \\ Erica Iceberg \\ Laura McKeel
}

Follow this and additional works at: https://digitalcommons.hope.edu/faculty_publications

Part of the Psychology Commons

\section{Recommended Citation}

Inman, Mary, Erica Iceberg, and Laura McKeel. “Do Religious Affirmations, Religious Commitments, or General Commitments Mitigate the Negative Effects of Exposure to Thin Ideals?" Journal for the Scientific Study of Religion 53, no. 1 (March 1, 2014): 38-55. doi:10.1111/jssr.12089.

This Article is brought to you for free and open access by Hope College Digital Commons. It has been accepted for inclusion in Faculty Publications by an authorized administrator of Hope College Digital Commons. For more information, please contact digitalcommons@hope.edu. 
Running head: RELIGION, COMMITMENT, AND BODY IMAGE

Do Religious Commitments, General Commitments, or Religious Affirmations Mitigate the Negative Effects of Exposure to Thin Ideals?

Mary Inman, Laura McKeel, \& Erica Iceberg Hope College

Published in The Journal for the Scientific Study of Religion, 53(1), 38-55.

Acknowledgements: We thank Kris Homan and Jane Dickie for their feedback on an earlier version of this paper, the $\underline{J S S R}$ editor and anonymous reviewers for their suggestions, and the researchers who helped with the data collection-Angelo Agalo, Amanda Milliken, Amber DeGraaf, Bradley Fong, Jessica Breslin, Mary Tripp, and Danielle Johnson. This project was not funded by any agency. Correspondence should be addressed to Mary Inman, Department of Psychology, Hope College, 35 E. 12 $2^{\text {th }}$ St., Holland, MI 49423. E-mail: $\underline{\text { inman @ hope.edu }}$ 


\begin{abstract}
Western pressures for thinness tell women that having a thin body makes a person worthy. Two factors that may provide alternative means of self-worth are religion and/or being committed to a meaningful goal (general commitment). This study experimentally tested whether religiousaffirming statements buffered against exposure to thin models for everyone, or only for women with strong religious commitment. It also examined the relationships among religious commitment, general commitment, and body satisfaction. One hundred eleven women at a religious-affiliated college completed the commitment scales and baseline body measures. They were later randomly assigned to read one set of affirming statements, after which they then completed body measures again. Reading religious affirmations increased feelings of love and acceptance. Experimental results showed that religious commitment buffered against exposure to ultra-thin models: Women who were strongly (but not weakly) religiously committed and who read religious statements that affirmed the body showed higher body esteem. Correlation results showed that general commitment was positively related to body esteem, body satisfaction, and healthy dieting. Religious commitment was positively related to body esteem and body satisfaction. Results are discussed in relation to schemas and depth of processing. Practical implications are discussed.
\end{abstract}


Do Religious Affirmations, Religious Commitments, or General Commitments Mitigate the Negative Effects of Exposure to Thin Ideals?

The relationship between religion, body image, and dieting is historically complex and multifaceted (Gerber 2011; Griffith 2004; Boyatzis and Quinlan 2008). On the one hand, historians argue that Christians perceive obesity as a sign of sin (e.g., gluttony) and weakness in controlling one's urges (for reviews, see Gerber 2011 and Griffith 2004). The authors explain that churches promote self-control, healthy eating, and treating one's body as a temple to do God's work (Gerber 2011:11; Griffith 2004) which can result in feeling shame and guilt when one falls short. On the other hand, research has shown positive effects of religion: College students reported that prayer and religion helped them cope with bad body-image days (SmithJackson, Reel, and Thackeray 2011; Jacobs-Pilipski et al. 2005). Some overeaters explained that their religious beliefs helped reframe their priorities. They developed a meaningful life philosophy and controlled their food-related obsessions and behaviors (Griffith 2004).

Noticing this complexity, Hill and Pargament (2003) encouraged researchers to identify which aspects of religiosity have which effects in which populations. In attempts to answer this call, the present study examined how religious-affirming statements, religious commitment, and general commitment relate to women's body-image in a nondiagnosed female sample at a religious college. This study has two components: The experimental component tested the effects of various affirming statements on body esteem, to test a possible mediator (feeling loved) and to test a possible moderator (religious commitment). The correlational component examined relations between religious commitment, general commitment, and body satisfaction to identify possible mechanisms (e.g., commitment, transcendence) related to positive body image.

\section{Women's Normative Discontent}


Brumberg (2000) argued that modern Western society has replaced the goal of spiritual attainment with a physical beauty ideal, where women suffer to be thin rather than pious (Kim 2006:286). A reliable finding in body-image research is that a vast majority of Western young women are dissatisfied with their bodies (Griffith 2004; Striegel-Moore, Silberstein, and Rodin 1986), presumably because they internalized the Western ideal of an unrealistic thin body (Stice 2001). Western norms teach that being thin affords one with sexual confidence, power, and security, whereas being overweight makes one untrustworthy, ugly, and weak, sending the metamessage that to have social value, one must be thin (Brumberg 2000; Kim 2006:285).

Supporting this argument, women who reported they could not reach society's thin ideal showed greater body dissatisfaction and lower body esteem (Brownell 1991). In addition, frequent exposure to thin-idealizing media was related to greater body dissatisfaction in young women (Bissell and Zhou 2004; Grabe, Ward, and Hyde 2008; Groesz, Levine, and Murnen 2002; Homan 2012). Body dissatisfaction and low body esteem are negative outcomes in and of themselves, but they are also related to other psychological problems such as eating pathology, depression, and low self-esteem (Hargreaves and Tiggeman 2003; Levine, Smolak, and Hayden 1994; Stice 2001; Stice, Ng, and Shaw 2010). Thus, identifying factors that minimize body dissatisfaction is crucial in helping women's mental health. Three factors that we explore that could bolster self-worth and resist societal pressures to be thin are religious affirmations (beliefs), religious commitment, and general commitment.

\section{Religion and Body Image}

Religion may promote healthy body image by providing a source of self-worth (Steele, 1988) other than the body because it encourages people to connect to and serve God and relate 
well with others (Idler 1995; Kim 2006). Religion may serve as a self-schema (system of knowledge and beliefs about oneself used to process incoming information) in which a person bases self-worth on religious and spiritual principles (e.g., serving God, serving others) instead of having the thin body ideal (Avants, Warburton, and Margolin 2001; Kim 2006:286).

\section{Possible Mechanisms of Religion}

Given that religion is complex and multidimensional, different aspects of religion may affect body image differently, depending on beliefs about God, images of God, and differential experiences of believers (Francis, Gibson, and Robbins 2001; Kim 2006). Religion could bolster body esteem due to believing in God's unconditional love, being committed to an important meaningful goal, experiencing transcendence feelings (e.g., peace, inspiration) when relating to God and practicing religious acts, being accepted by a group, and/or receiving social support for self-regulation (Griffith 2004; Watterson and Giesler 2012). Testing all these mechanisms is beyond scope of this paper, yet the unconditional love aspect is tested by our study's experiment. The commitment and transcendent feelings aspects are tested by our correlation analysis.

\section{Experiment: Religious Beliefs Suggesting Unconditional Love}

Religion could minimize low body esteem because believers (a) feel unconditionally loved by God and so believe themselves to be acceptable and worthy (Boyatzis, Kline, and Backof 2007; Homan 2012; Smith-Jackson, et al 2011), (b) think that God is a secure base who can be trusted in stressful times (Homan 2012), and/or (c) believe that their body was made in God's image and thus is good (Boyatzis et al 2007; Mahoney et al 2005). Correlational evidence (with Western, primarily Christian samples) supports the latter two arguments: Research showed that women who reported a secure (versus anxious) attachment to God were less likely to 
internalize society's thin-body ideal and to report subsequent body dissatisfaction (Homan 2012; Homan and Boyatzis 2010). Viewing one's body as in God's image or as a manifestation of God was related to college students feeling good about their bodies (Mahoney et al. 2005). Our experiment tested the first argument that reading religious-affirming statements increases feelings of love and acceptance.

In a clever experiment that we extend, Boyatzis et al. (2007) proposed and tested whether women's low body esteem (from viewing thin models) could be prevented by having women, at a secular college, read religious statements that affirm the body. The authors argued that many religions promote beliefs pertaining to body image (e.g., assertions that people are made in the image of God, the body is a gift from God, the body is a temple of God, and that God is loving and forgiving:553). They assessed body esteem by appearance esteem and weight esteem in a pretest. In a later session, they manipulated the type of affirming statements. Specifically, the authors matched participants on body esteem pretest scores and randomly assigned women to read either 15 theistic-affirming statements that explicitly mentioned God and that acceptance and approval of one's body ("God has created my body, and I am able to see the divine perfection of my own body"), 15 affirming statements that spiritual in nature but did not mention God ("With love and joy, I am able to accept and embrace the body that I have"), or 15 control statements that gave facts about their college. The theistic affirming statements had some statements that causally linked the relationship to God with a higher status of the body (e.g., Because I am a child of God, I am perfect and whole and my body is perfect and whole) or that gave a balanced perspective of the body (e.g., Is life more than food, and the body more than clothing?)--two beliefs that highly religious people are likely to endorse (Boyatzis et al. 2007; Worthington et al. 2003). Four of the 15 theistic statements came from the Bible. Boyatzis et al. 
assessed body esteem afterwards and computed change scores. They found that women who read theistic/religious statements showed increases in their appearance esteem, women who read spiritual statements showed modest increases, and women reading control statements showed the expected decrease in appearance esteem. The manipulation did not affect changes in weight esteem.

To better understand the mechanisms involved, we extended this study in five ways. First, if the key mechanism in Boyatzis et al.'s theistic statement condition was triggering thoughts of God's unconditional love, religious-affirming statements that do $\underline{\text { not }}$ reference the body should elicit feelings of love too and subsequently increase body esteem, so we added another experimental (religious-nonbody) condition. Second, the implicit mechanism at work when reading religious statements may be feeling loved and accepted (by God), and this love may increase body esteem. Thus, we assessed feelings of love and acceptance after participants read the various statements and tested whether feelings of love explained (mediated) the statement effect on subsequent body esteem.

H1: Reading both kinds of religious statements should increase feelings of love and acceptance.

$\mathrm{H} 2$ : If religion makes women feel unconditionally loved, stronger feelings of love should be positively related to increased changes in body esteem.

H3: Reading the religious-body affirming statements should increase appearance esteem more than reading control statements, if Boyatzis et al.'s results are replicated.

Third, we included measures of other risk factors of eating disorders (i.e., drive for thinness, body dissatisfaction, and unhealthy dietary restraints) to examine relations with religious commitment and general commitment (described next). Given that the drive for 
thinness, body dissatisfaction, and restrictive dieting reflect how frequently people have had food-related thoughts and behaviors in the recent past (Garner, Olmstead, and Polivy 1983), we did not expect our brief statement manipulation to affect reports of past thoughts and behaviors.

Fourth, we tested whether religious commitment interacted with the affirmation manipulation. For reasons explained in the next section, people with a strong religious commitment should really feel affirmed when reading either type of religious-affirming statements and thus, have more positive body esteem, compared to weakly committed women. In addition, we tested whether women with strong religious commitment had more positive body image in general (at pretest, at post-test) in our correlational analysis. Fifth, we examined the relation between general commitment and body image to identify possible mechanisms (e.g., commitment to a meaningful goal, transcendent feelings) and to test whether religious commitment predicted positive body image beyond general commitment.

\section{Correlations: Religious Commitment}

People can report being religious but vary in their religious commitment. Religious commitment is the extent to which one adheres to the values, beliefs, and practices of their own religion in their daily living internally and externally (Worthington et al. 2003). This includes membership in religious organizations, degree of participation in religious activities, and attitudes related to the importance of religious experience. The authors explain that a highly religious person has integrated religion into much of his/her daily life. A religiously committed person spends time reflecting on religious beliefs, applying religion to all aspects of life, reading books about one's faith, and supporting and interacting with people from one's religious 
organization. These concepts are assessed in Worthington et al.'s religious commitment scale (2003:85,87).

Research suggests that women with high religious commitment should have a more positive body image than women low in religious commitment: Women who placed importance on religion (Joughin et al. 1992), who attended worship regularly (Mahoney et al. 2005), who had an intrinsic orientation (Forthun, Pidcock, and Fischer 2003), or who spent more hours given to religion (Kim, 2006) had a healthier body image than their counterparts.

We propose that religion offers the opportunity to select (and work towards) meaningful goals that transcend to God. Religious leaders encourage people to read and pray to become closer to God, submit to God, serve others, excel in one's work, and build strong social ties (Griffith, 2004:169, 189, 191). Griffith's interviews with dieters revealed that some people explained that food, dieting, and overeating became an idol (or obsession). They chose to reprioritize their life to submit to God, build a relationship with God, and to do God's work which brought a meaningful direction, closeness to God, and closeness to others (Griffith 2004:169, 188). Idler (1995) found similar patterns with disabled people. Idler explained that for religious people who were disabled, religion promoted a spiritual self-definition: The person attempted to better know God through reading Scripture and worked to make meaning of his/her ailment (687). Idler (1995) found that strongly religious people with disabilities minimized the importance of their ailing physical bodies, emphasized their spiritual nonphysical self, and reported better health than less religious people.

A close read of these interviews suggests that people who experienced this transcendence (connection) to God may have experienced several positive emotions such as peace and feeling 
affirmed, validated, encouraged, happy, reassured, inspired, and enlightened. We argue that religiously committed people should more readily experience these emotions given their religious efforts, schema, and experiences. Similarly, religiously committed people should report feeling loved and accepted by God more than people low in religious commitment. These Godrelated transcendence emotions should be uniquely related to religious commitment and not general commitment (explained next).

H4: Women high (but not low) in religious commitment should report greater body esteem, body satisfaction, less drive for thinness, less restrictive dieting, stronger transcendence emotions, and greater love and acceptance.

By combining religious commitment with our affirming-statement manipulation, we assessed the influence of each factor on changes in body esteem. The internalized religious beliefs (e.g., God's love for imperfect people) and mandates (e.g., set your minds on things of the Spirit. Love your blessed body) of highly religious women could be related to increased body esteem in all conditions (yielding a main effect) if these beliefs are internalized, accessible, and used when viewing images of thin women. It may be, however, that young women have not given much thought about the specific religious passages that affirm the body. When reading religiousbody affirmations, differential processing between religious groups will likely occur because the highly committed women have a working religious schema and more motivation to deeply process religious material (Worthington et al. 2003). This prediction is based on the Elaboration Likelihood Model which proposes that people will critically evaluate information when they are motivated or able to do so (Petty and Cacioppo 1986). By definition, people who are religiously committed are motivated to think about religious material. We predicted increases in body esteem when high (but not low) religiously committed women read religious-body-affirming 
statements because religious-body statements could remind committed people of their personal beliefs of God's love for them and their bodies and their religious priorities (serving God versus worrying about body image). Reading the religious-nonbody statements could trigger these body-affirming beliefs in committed women, resulting in increased esteem, if religious bodyaffirming beliefs are internalized, accessible, and used. Religiously committed women should weigh the religious-body statements more heavily and internalize the affirmations into their self schema. For women who are low in religious commitment, both kinds of religious statements might seem like novel positive platitudes, as they have not internalized the statements into a meaningful personal philosophy.

H5: Religiously committed women should show greater increases in body esteem (main effect). Highly religious committed women who read religious-body (and perhaps nonbody) statements should show increases in body esteem compared to women low in religious commitment and women reading control statements. This statement $\mathrm{x}$ religious commitment interaction effect should remain after removing the effect of general commitment.

\section{Correlations: General Commitment}

The religious-commitment prediction begs the question of whether having meaningful commitments to anything is related to a positive body image. General commitment is the extent to which one is dedicated and motivated toward any activity, program, group, or person (Brickman 1987). According to commitment theory, people who are generally committed have freely chosen to dedicate themselves to something (e.g., friends, family, teams, academics) and take responsibility for this decision. Committed people report conviction that whatever they have chosen in their lives is worthwhile and important (Brickman 1987). They showed a visible 
enthusiasm, vigor, and zest for life (Brickman 1987:227). Being committed increases motivation and focus and gives purpose to life. Brickman's (1987) general commitment scale assesses the degree to which a person is open to commitments ("I am willing to make commitments"), makes sacrifices for goals, and persists towards self-defined goals ("When I get going on something, I cannot quit until it is done").

Evidence shows that people with strong commitments (e.g., to love partners, to religion, to one's career) were happier and content with life (Brickman 1987). In terms of body image, this suggests having commitments improves one's ability to cope with stressors (e.g., seeing thin models) because the person has different meaningful goals that he/she is pursuing.

H6: Women high (but not low) in general commitment should show greater body esteem, body satisfaction, less drive for thinness, and less restrictive dieting.

General commitment was chosen because it shares some self-affirming features with religious commitment (i.e., openness to make a commitment, committing to a meaningful goal, efforts towards this goal) and yet has some differences: General commitment omits any desire to connect to God, grow in faith, and make faith-based goals. It omits experiencing emotions (e.g., peace, inspiration, love from God) related to religious transcendence -- key emotions that may relate to positive body image. Thus, we allowed general commitment to predict changes in body esteem before examining any effects of religious commitment. Doing so allows us to test the incremental validity of religious commitment on body esteem. No studies have examined general commitment and body image.

\section{Method}

\section{Participants}


A total of 111 women $(M=18.8$ years, $S D=1.2)$ in introductory psychology courses at a private college participated in two sessions as one way to earn class credit. Most (87\%) were Caucasian and $95 \%$ reported they were Christian. In order to make direct comparisons to Boyatzis et al.'s (2007) work, we used several of their procedures (e.g., excluding diagnosed or nonreligious participants, matching, religious-body and spiritual statements, ANCOVAs). Given that our experiment showed thin models, we excluded women who self-reported that they had been diagnosed with an eating disorder $(N=16$, anorexia nervosa or bulimia nervosa). They were given alternative materials in the second session and were not included in the final sample. Like Boyatzis et al. (2007), we also omitted any women whose responses showed they were extremely nonreligious, defined as showing at least four of these five criteria: they never prayed, never attended worship services, did not belong to a religious denomination, classified themselves as neither religious nor spiritual, and indicated that religion was not at all important to them $(N=4)$, resulting in a final sample of 111 women. The final sample showed a variety of responses (e.g., rarely pray to pray daily). A total of $83 \%$ of our sample said religion was very or extremely important, whereas $39 \%$ of Boyatzis et al.'s (2007) sample answered this way. Our sample varied in religious commitment, however. See the Descriptive Statistics section.

\section{Procedure}

Overview. Women completed two sessions two weeks apart. Time 1 included the pretest with the commitment scales, demographic questions including height and weight, to calculate body mass index (BMI), and all body-image measures (i.e., drive for thinness, dieting, body dissatisfaction, and body esteem). Time 2 included the religious-statement manipulation, emotion assessment, exposure to thin models, and all body measures again. 
Specifically, during Time 1, women answered 123 items online privately and were told they were eligible to complete the "Media Study" held two weeks later. Like Boyatzis et al., we matched participants on self-reported importance of religion and Time 1 overall body esteem. The matched sets were randomly assigned to the four statement conditions. The mean Time 1 body esteem scores did not differ, $F(3,107)=0.07, p=.97, \eta^{2}=.00$, indicating that the conditions were comparable.

At Time 2, women completed three different tasks in groups of 12 to 16 two weeks later. Participants were seated away from others to ensure privacy and were told their responses were anonymous. The first task was the statement-affirming manipulation. After reading the 15 statements for 3 minutes, they were asked to summarize the statements in a sentence to reinforce the manipulation. They then indicated their emotions after having read the statements. Task 2 showed six photographs of fashion models to all participants for 4 mins. The black-and-white photos had no text on them and were taken from online, noncopyrighted sources. Models were generally the same age as participants, had thin arms and legs, and were not endorsing a product. We used six photographs because experiments have shown that exposure to fewer than 10 images produced large effect sizes (Groesz et al. 2002). Task 3 asked women to complete the body esteem, body dissatisfaction, drive for thinness, and restrictive dieting scales. Participants were thanked and debriefed. The order of the scales was counterbalanced for Time 1 and Time 2 .

\section{Measures and Materials}

General commitment (Time 1 only). At Time 1, we used the 30-item General Commitment Scale (Brickman 1987) which assessed the willingness to make commitments, have commitments, and find value and meaning in certain tasks (e.g., "I am committed to a few special things in my life. I know what the top priority in my life is"). Participants indicated 
agreement $($ false $=0, \underline{\text { true }}=1)$. Reverse-worded items were scored such that total (summed) scores reflected stronger general commitment. Reliability coefficients are shown in Table 1.

Religious commitment (Time 1 only). We measured religious commitment during Time 1 using Worthington et al.'s (2003) 10-item Religious Commitment Scale which has shown good reliability, factor structure, and construct validity in many samples. It assessed attitudes of the importance of religion and adherence to religious beliefs and practices (e.g., "I spend time trying to grow in understanding of my faith"). Participants indicated agreement on a 5-point scale $(1=$ not at all true of me, $5=$ totally true of me) . Scores were summed to make a religious commitment score, with higher scores indicating stronger religious commitment.

Statement-affirmation manipulation (Time 2). Each of the three experimental groups read a different set of affirmations that were meant to be uplifting in nature. Each group read their 15 statements for 3 minutes and then summarized the content in a sentence. The religiousbody statements were taken from Boyatzis et al. (2007). See their Appendix. Their research team wrote theistic body-affirming statements. In the religious-body condition, their statements were explicitly theistic because most mentioned God; many were Christian-based, four were quotations from the Bible (e.g., "Do you not know that your body is a temple of the Holy Spirit within you, which you have from God?...So glorify God in your body"), and others were inspired by New Testament Biblical passages. They explained that their theistic content was consistent with the definition of "religious" for most Americans (556). The positive/spiritual condition read 15 similar affirmations but with no reference to God, directly taken from Boyatzis et al. (e.g., "Because I love my body, I consider it to be perfect and whole." "I will my body to be cleansed and set free from all imperfections and disharmonies." "The spirit of life is expressed in my body.”). See their Appendix. These affirmations emphasize a positive and holistic view of the 
body without any explicit religious intonations (Boyatzis et al. 2007:556) and were pilot tested by the authors and rated somewhat to strongly spiritual. The religious-nonbody condition read our newly created 15 statements that were meant to affirm the religiosity of the participants, were positive in nature, and did not reference the body. We selected Bible verses that instilled personal affirmation, love, and encouragement ("Be joyful in hope, patient in affliction, and faithful in prayer."). The control condition read our newly created 15 statements about facts on our college (modeled after Boyatzis' et al.'s control condition). Control statements described the college's size of the freshmen class, historical dates, academic and social activities, and travel programs. (e.g., "[Name of college] first opened in [year] as [original name]").

Emotions (Time 2 only). We asked participants, "the extent to which you felt [emotion] after reading the statements," using a 9-point scale $(1=\underline{\text { not at all }}, 9=\underline{\text { extremely }})$. Fourteen emotions were listed with two being loved and accepted. We averaged responses to create a love/acceptance emotion score $(\alpha=.93)$. Five items were fillers (e.g., informed, obligated, anxious) and seven emotions reflected those emotions associated with religious transcendence (Griffith 2004). Exploratory factor analyses showed the seven emotions (at peace, affirmed, encouraged, happy, reassured, enlightened, inspired) loaded highly (.73 - .89) on one factor. Responses were summed and mean centered to make a transcendence score $(\alpha=.93)$.

Body esteem (BE, Time 1 and Time 2). Body esteem was measured using Mendelson, Mendelson, and White's scale (2001), with subscales assessing how women felt about their appearance (BE-APP 13 items, "I'm as nice looking as most people.") and weight (BE-Wt, 4 items, "I feel I weigh the right amount for my height.") to assess changes after the manipulation. Subscales were used to allow direct comparisons with Boyatzis et al.'s results. Women indicated how often they agreed with the statements on a 5 -point scale $(1=\underline{\text { never }}, 5=\underline{\text { very often }})$. Reverse- 
worded items were recoded so that high numbers reflect more positive appearance or weight esteem. We summed responses to the BE-Wt times at Time1 and summed responses to the BEWt items at Time 2 to create total BE-Wt scores at Time 1 and 2, respectively. To examine changes in BE-Wt, we subtracted a person's BE-Wt Time score 1 score from her BE-Wt Time 2 score. An identical scoring rubric was used to make BE-App scores Time 1, Time 2, and BEAPP difference scores. Positive difference scores reflect more positive esteem Time 2 than Time 1. Identical results occurred when we computed averages rather than sums.

The next three body-image measures were used to assess their relationships with general commitment and religious commitment. We did not expect the brief statement manipulation to affect changes in these measures of past behaviors and attitudes.

Drive for thinness (Time 1 and Time 2). The drive for thinness was assessed using Garner et al.'s (1983) 7-item Drive for Thinness scale and scoring rubric. Items measured women's frequency of thoughts of being overweight and pursuit of thinness ("I feel extremely guilty after overeating.") on a 6-point scale $(1=\underline{\text { never }}, 6=\underline{\text { always }})$. The scores were then converted so that the top score (6) received 3 points, the next highest score received 2 points, the third score received 1 point, and the remaining scores received 0 points. Scores were summed to make a total drive for thinness score with a higher score indicating a greater desire to be thin.

Restrictive dieting (Time 1 and Time 2). We gave Paxton, Wertheim, and Muir's (1999) 10-item restrictive dieting scale that assessed how frequently women engaged in several restrained behaviors in order to lose weight (e.g., skip meals, diet, vomit, take laxatives, etc.) Time 1 and Time 2 using a 5-point scale $(1=\underline{\text { never }}, 5=\underline{\text { very often }})$. Scores were summed with higher scores reflecting more restrictive dieting. 
Body dissatisfaction (BD, Time 1 and Time 2). We gave Garner et al.'s (1983) 9-item scale that assessed frequency of dissatisfied thoughts with one's stomach, hips, thighs, and general shape of one's body, using the same 6-point response scale $(1=\underline{\text { never }}, 6=\underline{\text { always }})$ and 0 to 3 scoring rubric as the drive for thinness scale. Responses were summed, with high scores reflecting greater body dissatisfaction.

\section{Results}

The results are presented in three sections: Descriptive statistics are presented first. We then ran manipulation checks and tested the hypotheses involving the experimental manipulation (H1, H2, H3, and H5) with ANOVAs and ANCOVAs. We then tested hypotheses about religious commitment, general commitment, and emotions and body image (H4, H6) with correlations.

\section{Descriptive Statistics}

Table 1 shows descriptive statistics for the measures, including reliability coefficients. In our sample, women's average BMI was 22.25 which was nearly identical to Boyatzis et al.'s sample's BMI (22.24). In our sample, the average general commitment was higher $(M=21.76)$ than the midpoint of the scale (15). Our women's average religious commitment $(M=31.47)$ was higher than that seen in university samples $(M=23-25.7)$ and lower than Worthington et al.'s (2003) samples of Christian students at explicitly Christian colleges $(M=38.5)$.

$$
\text { Insert Table } 1 \text { about here }
$$

\section{Experimental Effects}

Manipulation checks. The statements in the three experimental groups were meant to affirm people. Surprisingly, a oneway (condition) ANOVA on feeling affirmed showed no significant differences among conditions, $F(3,106)=0.39, p=.76($ Mcontrol $=5.96, S D=2.22$; Mpositive $=6.21, S D=1.50$, MReligious-nonbody $=6.22, S D=2.08 ;$ MReligious-body $=6.55$, 
$S D=2.21$ ). All means were above the scale's midpoint. In addition, the thin pictures posed a threat to some women (29 percent of our sample showed decreases in body esteem over time).

Statement manipulation and emotions (H1). We ran a oneway (condition) ANOVA on feelings of love and acceptance to test whether religious statements increased these feelings (H1). The statement-condition effect on feelings of love and acceptance was significant, $F(3$, $106)=8.22, p<.001$. Planned contrasts showed, as predicted, women in the two religious conditions felt more loved and accepted (MReligious nonbody $=7.59, S D=1.85 ;$ MReligious body $=7.41, S D=1.79)$ than women in the other two conditions $($ Mcontrol $=5.22, S D=1.90$; Mpositive $=6.73, S D=2.25), t(106)=4.08, p<.001$.

Emotions and body esteem (H2): Interestingly, women who felt the most loved and accepted did not report higher BE-weight or BE-appearance Time 2, $r s<.05, p s>.44$, or changes on these measures, $r s<.05, p s>.57$, refuting the idea that feelings of love mediates the manipulation's effect on body esteem.

\section{Statement manipulation, religious commitment, and body esteem (H3, H5). Like}

Boyatzis et al., we ran the same analysis (ANCOVA) on change scores, though we added general commitment scores as a covariate. Preliminary analyses showed a) that general commitment did not interact with the statement manipulation, in affecting body esteem, $p s>.60$ and b) similar results when we conducted a within-subjects ANCOVA on Time 2 body esteem scores and added Time 1 esteem scores as a third covariate.

We created two religious-committed groups and ran two 2 (level of religious commitment) x 4 (condition) ANCOVAs on changes in appearance and weight esteem, using BMI as a covariate (like Boyatzis et al. 2007) and general commitment as a covariate. 
Preliminary analyses showed that BMI did not interact with the statement condition or religious commitment in affecting appearance or weight esteem, $p s>.32$.

We created two religious-committed $(\mathrm{RC})$ groups based on a median split $(\leq 33$ were lows, $\geq 34$ were highs). The distribution of scores was symmetrically distributed (skew $=-0.27)$. The mean was near the median $(M=31.49, M d n=33) .{ }^{1}$ The means for changes in appearance and weight esteem are shown in Table 2. The 2 (RC) x 4 (condition) ANCOVA on changes in appearance esteem showed the statement effect was not significant, $F(3,101)=0.29, p=.83$, refuting $\mathrm{H} 3$ and not replicating Boyatzis et al. Women reading the religious-body statements did not report higher appearance esteem $(M=4.68, S D=7.87)$ than women reading control statements $(M=3.74, S D=6.51)$. The general commitment covariate was not significant, $F(1$, $103)=2.76, p=.10$; the BMI covariate was not significant, $F(1,101)=0.02, p=.90$; and the religious commitment main effect was not significant, $F(1,101)=1.27, p=.26$. The expected condition $\mathrm{x}$ RC interaction was significant, $F(3,101)=2.99, p<.04, \eta^{2}=.08$. Because the

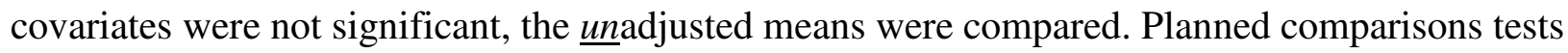
showed, in the religious-body condition, women $\underline{\text { high }}$ in religious commitment showed increases in appearance esteem compared to women $\underline{\text { low }}$ in religious commitment reading religious-body statements, $t=3.05, p<.006$, highly religious women reading the $\underline{\text { control }}$ statements, $t=3.34, p$ $<.004$, and highly religious women reading the religious- $\underline{n o n b o d y}$ statements, $t=2.68, p<.02$. Taken together, these results partially support H5.

Insert Table 2 about here

The $2 \times 4$ ANCOVA results on changes in weight esteem showed similar effects (see Table 2). The statement main effect was not significant, $F(3,101)=0.52, p=.60$, replicating Boyatzis et al.'s null finding. The general commitment covariate was not significant, $F(1,103)=$ 
$1.96, p=.17$; the BMI covariate was not significant, $F(1,101)=2.89, p=.09$; and the religious commitment main effect was not significant, $F(1,101)=2.71, p=.60$. The expected condition $\mathrm{x}$ RC interaction was significant, $F(3,101)=3.42, p<.03, \eta^{2}=.09$, such that religious-body statements buffered body threats in highly religious women. Comparisons tests showed, in the religious-body condition, women $\underline{\text { high }}$ in religious commitment showed increases in weight esteem compared to women $\underline{\text { low }}$ in religious commitment reading religious-body statements, $t=$ $2.11, p<.05$, and highly religious women reading the control statements, $t=2.17, p<.04$, partially supporting H5.

\section{Correlations}

Religious commitment and emotions (H4). As expected, women who were strongly committed to religion reported stronger transcendence emotions than women weakly committed to religion, $r(106)=.33, p<.001$. Removing the effects of general commitment did not attenuate this relationship, partial $r(106)=.33, p<.001$, as general commitment was not related to transcendence emotions, $r(109)=.07, p=.46$. Transcendence emotions were not related to more positive body image at Time $2, r s(109)<.11, p s>.24$ or change in body esteem, $r s(109)<.11$, $p s>$.24. Supplemental analyses showed that transcendence emotions were not affected by experimental condition. Also, as expected, religious commitment, $r(109)=.33, p_{s}<.001$ (but not general commitment, $r(109)=.07, p=.46)$, was related to feelings of love and acceptance. ${ }^{2}$

Religious commitment and body image (H4). Table 3 shows the relationships among the commitment and body-image measures at Time 1 and Time 2 (after reading the statements and viewing models). Note that religious commitment and general commitment were not related, $r(109)=.10, p=.31$. Religious commitment was positively related to appearance esteem, weight 
esteem, and body satisfaction at Time 2, but only the religious commitment/body satisfaction relationship remained when removing the effect of general commitment, weakly supporting H4.

Insert Table 3 about here

General commitment and body image (H6). General commitment was significantly related to four of the five body measures at Time 2, and removing the effects of religious commitment did not attenuate these relations (see Table 3). As predicted (H6), women with strong general commitments reported greater appearance and weight esteem, lower body dissatisfaction, and less restrictive dieting than women weak in general commitment. Interestingly, general commitment was more strongly related to body-image measures assessed at Time 2 (after seeing thin models) than body-image measures at Time 1.

\section{Discussion}

This study's experimental and correlational components examined how religious affirmations and commitments relate to women's body esteem. The experimental results showed that both kinds of religious-affirming statements increased feelings of love and acceptance in all women (supporting H1). These feelings did not directly correspond to positive body esteem, however (refuting H2). Also, reading religious-body-affirming statements did not increase body esteem in all women (refuting H3) but did so in religiously committed women (supporting H5). These effects remained, even after removing the effects of body mass and general commitment.

The correlational part of this study teased apart the elements of being committed to any meaningful goal (general commitment) and commitment to religious beliefs and practices. Religious commitment was related to body esteem and satisfaction (partially supporting H4), partially due to being committed to a meaningful goal. Religious commitment was uniquely related to feeling loved (by God) and transcendence feelings of peace and inspiration, yet these 
emotions were not directly related to higher body esteem. General commitment was more consistently related to a positive body image than was religious commitment. General commitment was positively related to body esteem, satisfaction, and healthy dieting (supporting H6). These findings support the ideas that religion (for some women) and general commitments can serve as bases of self-worth.

\section{Experimental results: Beliefs of God's unconditional love and religious commitment}

The experimental results extend prior work showing religion's positive effect on body image (Boyatzis et al. 2007) in several ways. First, this is the first study to show that both types of religious statements increased feelings of love and acceptance, supporting the idea that one important aspect of religion is certain religious beliefs may create a feeling that one is unconditionally loved by God (Boyatzis et al. 2007). Feelings of love did $\underline{\text { not }}$ readily correspond with positive body esteem, however, suggesting that the transference from feeling Divine acceptance to acceptance of one's body is complicated.

Though other possibilities exist, this disconnect between feeling loved and positive body esteem could be due to a) the women may have not deeply or routinely thought about the implications of a loving God who fully accepts them even with their bodily flaws (support for this is given below) and/or b) other religious beliefs (e.g., mandates to honor one's body, feeling obligated to avoid the sin of gluttony) and related emotions (guilt and shame) lowered body esteem. Additional analyses showed the importance of negative emotions: Women who reported feeling obligated (to something) reported lower appearance esteem, weight esteem, and body satisfaction, $r s>.19, p s<.05$ than women feeling less obligated. ${ }^{3}$ This finding shows the contradictory nature of having commitments (Brickman, 1987) and supports the argument that different aspects of religion may affect body image differently, depending on beliefs about God 
and images of God (Francis et al 2001). Our design shows it is useful to manipulate specific beliefs and assess conflicting emotions.

Second, when comparing across studies, our findings suggest different cognitive processes may be occurring in different samples. Recall Boyatzis et al.'s sample was from a secular college and the religious-body statements increased their appearance esteem. Our sample attended a religious college, many (83\%) said that religion was important to them yet they varied in religious commitment, and the religious-body statements increased body esteem more so in religiously committed women. Why the differential results? One might argue a novelty explanation, saying that the religious-body statements were novel, persuasive arguments to the secular sample. ${ }^{4}$ If so, then the same religious-body statements should be more novel and persuasive to our women who were weakly committed to religion. They should have shown larger increases in their body esteem, but this did not happen. The content of the religious-body statements of (i.e., Divine love, elevating the body's status, a balanced view of the body) should be old news to the highly religious (no novelty/persuasion effect), yet they were the ones showing the largest increases in body esteem.

We think schema theory (Kim 2006) and the elaboration likelihood model (Petty and Caccioppo 1986) can explain the increases in esteem in women strong in religious commitment (the group motivated to apply religion to their lives, Worthington et al. 2003). We think that women with a strong religious commitment who read religious-body affirmations more readily accepted and internalized the religious-body statements (revising their religious self-schema). They appeared to use the religious-body-affirming content in the moment to increase their body esteem. The results suggest our religiously committed women had $\underline{\text { not }}$ already internalized and integrated the key beliefs (e.g., Divine acceptance, elevating the body's status, a balanced view 
of the body) as they did $\underline{\text { not }}$ show heightened body esteem in $\underline{\text { all }}$ conditions or even when reading religious affirmations $\underline{n o t}$ mentioning the body. We think that women $\underline{\text { low }}$ in religious commitment (given their lower interest in applying religious passages to life), though temporarily persuaded, likely did not internalize either set of religious statements. Future research that further tests this model would be useful: Applying the Elaboration Likelihood Model, we predict that people high in religious commitment should think deeply and form more long-lasting body-affirming attitudes than people low in religious commitment and secular samples. Currently, we do not know if the esteem effects are long-lasting in either study.

\section{General Commitment and Religious Commitment}

Given the multifaceted nature of religion and religious commitment, we assessed general commitment to identify possible mechanisms in the religion-body relationship. Religious commitment involves committing and persisting towards a meaningful self-chosen goal and involves self-regulation (two similarities with general commitment). It also contains faith-based goals of knowing God by reading, discussions, and prayer; serving others; actively engaging in one's religious community; and more. General commitment involves being open to commitments, committing, and persisting towards one's goal. This is the first study to show that having a strong commitment for something was related to overall positive body esteem, body satisfaction, and healthy dieting (Time 2), and religious commitment did not attenuate these relations. These results are consistent with commitment theory (Brickman 1987), which posits that pursuing a meaningful goal (e.g., family, schoolwork) can give life purpose and meaning and provide a basis for self-worth. General commitment was not related to increases in body esteem after the potential threat of seeing thin models, suggesting that general commitment may be an overall protective factor. Because we did not manipulate general commitment, additional 
research is needed to identify which features of general commitment (e.g., self-control, selfefficacy beliefs, beliefs about the body's function versus appearance) affect body satisfaction.

Religious commitment is a more complex construct. We identified emotions (i.e., love/acceptance, transcendence emotions) that were theoretically and empirically related to religious commitment and not general commitment. These emotions were not directly related to positive body esteem, however, possibly because of the schema-building and cognitive reasons discussed earlier or because the emotions reflected how they felt after reading the statements and not how they felt in general. Correlational results showed removing general commitment did not affect increases in esteem when women read the religious-body statements, suggesting religious beliefs mattered. Removing the effects of general commitment did not attenuate the relationship between religious commitment and body satisfaction, suggesting other elements of religiosity (e.g., religious beliefs, support group) may be operating with body satisfaction.

\section{Practical Applications}

These findings have several implications for enhancing body image. First, the finding that any commitment was associated with a healthy body image suggests that prevention programs could help young women establish self-defined meaningful priorities, commit to them, see their successes in this domain, and ignore external media that suggest a thin-ideal body shape. Some of these basic elements (e.g., not perseverating over irrelevant worries, pursing valued behaviors) are seen in Acceptance and Commitment Therapy (Juarascio, Forman, and Herbert 2010) which was more successful than cognitive therapy in treating eating problems (Juarascio et al. 2010).

Second, we found that priming religious affirmations about the body to religiously committed women buffered against cultural messages suggesting thinness. Presenting religious affirmations is easy for therapists to do, but deepening one's religious commitment requires 
much cognitive elaboration, behavioral habits, and experience. Programs might introduce aspects of religious commitment (e.g., unconditional love from a trustworthy God). For example, priming secure attachments (including God) has been related to improving body image in college women (Homan 2012) and reducing distorted body perceptions in women with eating disorders (Mukulincer and Shaver 2010). Clearly, therapists and leaders would need to respect clients' beliefs, so this promotion of God's unconditional love might be more appropriate in churchrelated settings. Therapists implementing unconditional love and life's purpose have been successful with young Christian women with eating disorders (Richards et al. 2006). Finally, our finding of somewhat poor body image in people who claimed they were religious but were $\underline{\text { low }}$ in religious commitment suggests this subgroup may be at risk for body-image problems. For example, Homan (2012) found low body image in women who reported being religious yet doubted their relationship with God. It may be this subgroup's negative emotions and/or interpretations are related to their susceptibility to societal pressures and body dissatisfaction. These findings also suggest that researchers should avoid using one-item self-report religiosity measures as proxies for complicated religious constructs.

\section{Limitations and Conclusions}

This study has several limitations, despite the strength of using an experimental manipulation. First, the participants were women attending a Christian college with most being White, upper-middle class, and religious. Thus, these findings may only apply to similar populations. Generalizability to other gender, ethnic, economic, and religious groups may be limited. Second, the present results are based on the strength of our manipulations and measures. If we had used color photographs, we might have activated stronger body-image concerns. Though we used prior statement manipulations, nearly all participants felt affirmed (above the 
midpoint of the scale) even after reading the control statements (college facts) that were $\underline{\text { not }}$ meant to be affirming. Some facts listed student groups and programs that participants might have been involved in. Thus, perhaps our control group did not show the expected decrease in body esteem because they affirmed themselves by their college selection/activities. Even so, the religious-body statements increased esteem more than the control statements in highly religious women. Third, the body-esteem results suggest that participants had a difficult time differentiating between the three experimental affirming conditions, much like Boyatzis et al's sample did. In both studies, the religious-body group did not differ from the positive/spiritual group in their appearance esteem, suggesting that both body-affirming statements were somewhat helpful. Fourth, this study was part correlational, so causation remains tentative and the precise mechanisms of commitments and self-affirmation remain unclear. For example, we did not directly test whether participants placed greater importance on non-appearance domains when they saw thin models. Finally, we relied on self-report measures which may raise concerns about validity.

Despite these limitations, the present study extends prior research in several ways. It adds to the growing literature on religion and body image by identifying key emotions related to religious beliefs and religious commitment. It showed that religious commitment and religiousbody affirmations increased body esteem when young women were exposed to thin models. Finally, it was the first to show that the pursuing an important goal (general commitment) is an important predictor of positive body image and that general commitment partially explained why religious commitment was related to positive body esteem. 
Footnotes

1. Dichotomizing religious commitment scores by a median split has disadvantages (e.g., increases in Type 1 error, analysis has less power and ignores individual differences, MacCallum et al. 2002). Importantly, however, when religious commitment (RC) scores were kept continuous and we entered BMI and general commitment first, then condition and religious commitment, and then the $\mathrm{RC} \mathrm{x}$ condition interaction to predict change scores in a hierarchical regression, identical results emerged. Identical results were found when variables were mean centered.

2. A 2(level of religious commitment) $\mathrm{x} 4$ (condition) ANCOVA on transcendence emotions with general commitment as a covariate showed only a significant religious commitment effect, $F(1,101)=7.16, p<.01$. The general commitment covariate was not significant, $p=$ .40 ; the condition effect was not significant, $p=.18$, and the religious commitment $\mathrm{x}$ condition interaction effect was not significant, $p=.24$. A $2 \times 4$ ANCOVA on feelings of love and acceptance with general commitment and BMI as covariates showed a positive relationship between religious commitment and feeling loved, $F(1,100)=4.07, p<.05$, and significant condition effect, $p<.001$. The general commitment covariate was not significant, $p=.84$; the BMI covariate was not significant, $p=.54$, and the religious commitment $\mathrm{x}$ condition interaction effect was not significant, $p=.77$.

3. Feeling obligated was not predicted by BMI, general commitment, religious commitment, condition, nor the religious commitment x condition interaction. A 2 x 4 ANCOVA on feelings of obligation showed no significant effects, $p s>.21$.

4. We thank an anonymous reviewer for this argument. 


\section{References}

Avants, S. Kelly, Laura A. Warburton, and Arthur Margolin. 2001. Spiritual and religious support in recover from addiction among HIV-positive injection drug users. Journal of Psychoactive Drugs, 33(1):39-45.

Bissell, Kimberly L. and Peiqin Zhou. 2004. Must-see TV or ESPN: Entertainment and sports media exposure and body-image distortion in college women. Journal of Communication, 54(1):5-21.

Boyatzis, Chris, Sarah Kline, and Stephanie Backof. 2007. Experimental evidence that theistic-religious body affirmations improve women's body image. Journal for the Scientific Study of Religion, 46(4):553-64.

Boyatzis, Chris and Katherine Quinlan. 2008. Women's body image, disordered eating, and religion: A critical review of the literature. Research in the Social Scientific Study of Religion, 19:183-208.

Brickman, Philip. 1987. Commitment, conflict and caring. Englewood Cliffs, NJ: Prentice-Hall, Inc.

Brownell, Kelly D. 1991. Dieting and the search for the perfect body: Where physiology and culture collide. Behavior Therapy, 22(1):1-12.

Brumberg, Joan J. 2000. Fasting girls: The history of anorexia nervosa. New York: Vintage.

Forthun, Larry F., Boyd W. Pidcock, and Judith L. Fischer. 2003. Religiousness and disordered eating: Does religiousness modify family risk? Eating Behaviors, 4:7-26.

Francis, Leslie J., Harry M. Gibson, and Mandy Robbins. 2001. God images and self-worth among adolescents in Scotland. Mental Health, Religion, and Culture, 4:103-108.

Garner, David M., Marion P. Olmstead, and Janet Polivy. 1983. Development and validation of a multidimensional eating disorder inventor for anorexia nervosa and bulimia. International Journal of Eating Disorders, 2(2):15-34. 
Gerber, Lynne. 2012. Seeking the straight and narrow: Weight loss and sexual orientation in Evangelical America. Chicago, IL: University of Chicago Press.

Grabe, Shelly, L. Monique Ward, and Janet Shipley Hyde. 2008. The role of media in body-image concerns among women: A meta-analysis of experimental and correlational studies. Psychological Bulletin, 134(3):460-476.

Griffith, R. Marie. 2004. Born again bodies: Flesh and spirit in American Christianity. Berkeley, CA: University of California Press.

Groesz, Lisa M., Michael P. Levine, and Sarah K. Murnen. 2002. The effect of experimental presentation of thin media images on body satisfaction: A meta-analytic review. International Journal of Eating Disorders, 31(1):1-16.

Hargreaves, Duane, and Marika Tiggeman. 2003. Longer-term implications of responsiveness to "thinideal" television: Support for a cumulative hypothesis of body image disturbance. European Eating Disorders Review,11(6):5-477.

Hill, Peter C. and Kenneth I. Pargament. 2003. Advances in the conceptualization and measurement of religion and spirituality: Implications for physical and mental health research. American Psychologist, 58(1): 64-74.

Homan, Kristin and Chris Boyatzis. 2010. The protective role of attachment to God against eating disorder risk factors: Concurrent and prospective evidence. Eating Disorders, 18(3):239-258.

Homan, Kristin. 2012. Attachment to God mitigates negative effect of media exposure on women's body image. Psychology of Religion and Spirituality, 4(4):324-331.

Idler, Ellen L. 1995.Religion, health, and nonphysical senses of self. Social Forces 74(2):683-704. 
Juarascio, Adrienne S., Evan M. Forman, and James D. Herbert. 2010. Acceptance and commitment therapy versus cognitive therapy for the treatment of comorbid eating pathology. Behavioral Modification, 34(2):175-190.

Jacobs-Pilipski, M. Joy, Andrew Winzelberg, Denise Wilfley, Susan Bryson, and C. Barr Taylor. 2005. Spirituality among young women at risk for eating disorders. Eating Behaviors, 6(4), 293-300.

Joughin, Neil, Arthur H. Crisp, Christine Halek, and Heather Humphrey. 1992. Religious belief and anorexia nervosa. International Journal of Eating Disorders, 12(4):397-406.

Kim, Karen Hye-cheon. 2006. Religion, body satisfaction and dieting. Appetite, 46(3):285-296.

Levine, Michael, Linda Smolak, and Helen Hayden. 1994. The relation of sociocultural factors to eating attitudes and behaviors among middle school girls. Journal of Early Adolescence, 14(4):472-91.

MacCallum, Robert C., Shaobo Zhang, Kristopher J. Preacher, and Derick D. Rucker. 2002. On the practice of dichotimization of quantitative variables. Psychological Methods, 7(1):19-40.

Mahoney, Annette, Robert A. Carels, Kenneth I. Pargament, Amy Wachholtz, Laura Leeper, et al. 2005. The sanctification of the body and behavioral health patterns of college students. International Journal for the Psychology of Religion, 15(3):221-38.

Mendelson, Beverley K., Morton J. Mendelson, and Donna R. White. 2001. Body-Esteem Scale for Adolescents and Adults. Journal of Personality Assessment, 76(1):90-106.

Mikulincer, Mario and Phillip R. Shaver. 2010. Attachment in adulthood: Structure, dynamics, and change. New York: Guilford Press. 
Paxton, Susan J., Helena K. Schutz, Elenor H. Wertheim, and Sharry L. Muir. 1999. Friendship clique and peer influences on body image attitudes, dietary restraint, extreme weight loss behaviors and binge eating in adolescent girls. Journal of Abnormal Psychology, 108(2):255-66.

Petty, Richard E. and John T. Cacioppo. 1986. Communication and persuasion: Central and peripheral routes to attitude change. New York: Springer-Verlag.

Richards, P.Scott, Randy Hardman, and Michael Berrett. 2007. Spiritual approaches in the treatment of women with eating disorders. Washington, DC: American Psychological Association.

Smith-Jackson, TeriSue, Justine J. Reel, and Rosemary Thackeray. 2011.Coping with "Bad Body Image Days": Strategies from first-year young adult college women. Body Image, 8(4):335-342.

Steele, Claude M. 1988. The psychology of self-affirmation: Sustaining the integrity of the self. In Advances in experimental social psychology, edited by Leonard Berkowitz, pp. 261-302. New York: Academic Press.

Stice, Eric. 2001. A prospective test of the dual-pathway model of bulimic pathology: Mediating effects of dieting and negative affect. Journal of Abnormal Psychology, 110(1):124-135

Stice, Eric, Janet Ng, and Heather Shaw. 2010. Risk factors and prodromal eating pathology. Journal of Child Psychology and Psychiatry, 51(4):518-525.

Striegel-Moore, Ruth H., Lisa R. Silberstein, and Judith Rodin. 1986. Toward an understanding of risk factors for bulimia. American Psychologist, 41(3):246-63.

Watterson, Kaylyn and R. Brian Giesler. 2012. Religosity and self-control: When the going gets tough, the religious get self-regulating. Psychology of Religion and Spirituality, 4(3):193-205.

Worthington, Everett L., Nathaniel G. Wade, Terry L. Hight, et al. 2003. The religious commitment inventory-10: Development, refinement, and validation of a brief scale for research and counseling. Journal of Counseling Psychology, 50(1):84-96. 
Table 1

Descriptive statistics on commitment variables and body-image variables

\begin{tabular}{lcccc}
\hline & $M$ & $S D$ & $\alpha$ & Range \\
\hline Body Mass Index & 22.25 & 2.96 & --- & $15.2-36.6$
\end{tabular}

Commitment variables

General commitment

21.76

3.80

$.65 \quad 11-29$

Religious commitment

31.47

10.03

$.94 \quad 10-49$

Body-image variables

Appearance esteem

Time 1

Time 2

Weight esteem

Time 1

Time 2

Body dissatisfaction

Time 1

Time 2

Drive for thinness

Time 1

Time 2

Restrained dieting

Time 1

14.58

14.54

Time 2
9.30

9.63

13.05

14.09

5.71

5.59

4.01

3.27

3.89

$.87 \quad 0-17$
$.89 \quad 20-65$

$.94 \quad 21-64$

4.08

$.76 \quad 10-29$

4.15

$.79 \quad 10-32$ 
Table 2

Changes in Appearance and Weight Esteem by Religious Commitment Level and Condition

Level of Religious Commitment

\begin{tabular}{llll} 
& $\underline{\text { Low }}$ & & High \\
$n$ & $M(S D)$ & $n$ & $M(S D)$ \\
\hline
\end{tabular}

Changes in Appearance Esteem ${ }^{a}$

$\underline{\text { Affirmation Condition }}$

$\begin{array}{lllll}\underline{\text { Control }} & 14 & 5.43(7.99) & 13 & 1.92 \mathrm{~b}(3.97) \\ \underline{\text { Positive }} & 11 & 3.09(5.67) & 17 & 5.41(8.52) \\ \underline{\text { Religious-NonBody }} & 19 & 2.42(8.45) & 9 & 2.77(2.64) \\ \underline{\text { Religious-Body }} & 14 & 0.71 \mathrm{~b}(7.53) & 14 & 8.64 \mathrm{a}(6.17)\end{array}$

Changes in Weight Esteem ${ }^{a}$

Level of Religious Commitment

\begin{tabular}{llll} 
& $\underline{\text { Low }}$ & $\underline{\text { High }}$ \\
$n$ & $M(S D)$ & $n$ & $M(S D)$ \\
\hline
\end{tabular}

$\underline{\text { Affirmation Condition }}$

$\begin{array}{lllll}\text { Control } & 14 & 1.71(2.61) & 13 & 0.38 b(1.38)\end{array}$

$\begin{array}{lllll}\text { Positive } & 11 & 1.36(2.16) & 17 & 1.47(2.79)\end{array}$

$\underline{\text { Religious-NonBody }} 19 \quad 0.37(1.50) \quad 9 \quad 1.00(2.12)$

$\begin{array}{lllll}\text { Religious-Body } & 14 & -0.07 b(3.00) & 14 & 2.21 \mathrm{a}(2.72)\end{array}$

Note. For each dependent variable, row and column means with different letters differ significantly at $p<.05$. ${ }^{\text {a}}$ Positive changes reflect more positive esteem Time 2. 
Table 3

Correlations among Commitment Variables and Body-Image Variables Before (Time 1) and After (Time 2) Seeing Thin Models

$\begin{array}{lcccc}\text { Religious } & \underline{\text { Body Esteem }} & \begin{array}{c}\text { Body } \\ \text { Dissatisfaction }\end{array} & \begin{array}{l}\text { Drive for } \\ \text { Thinness }\end{array} & \text { Restrictive } \\ \text { Commitment } & \underline{\text { Appearance Weight }} & & \underline{\text { Dieting }}\end{array}$

$\underline{\text { Time } 1}$

Genera .10 $.25^{* *} \quad .18$ $-.32 * *$ $-.13$ $-.18$

Commitment

Religious

.09

.16

$-.09$

.03

.01

Commitment

Time 2

$.38 * * *$

$.25 * *$

$-.25 * *$

$-.10$

$-.21 *$

General

Commitment

$\begin{array}{llllll}\quad & (.37 * * *) & (.23 *) & (-.24 *) & (-.10) & \left(-.21^{*}\right) \\ \text { Religious } & .20 * & .19 * & -.21 * & .06 & -.07 \\ \text { Commitment } & & & & & \\ \quad \text { Partials } & (.17) & (.17) & (-.20 *) & (.07) & (-.06)\end{array}$

Note. $N=111$. Correlations in parentheses are partial correlations, either removing the effects of religious commitment or general commitment

$* * * p<.001, * * p \leq .01, * p \leq .05$. 
